\title{
IX \\ EDUCAÇÃO EM TRÂNSITO: OS DESAFIOS PARA \\ INCLUSÃO DE IMIGRANTES INDÍGENAS NA REDE DE \\ ENSINO*
}

\author{
Simone Santana Ferreira ${ }^{1}$ \\ Alan Augusto Ribeiro ${ }^{2}$
}

\section{Introdução}

Os movimentos migratórios contemporâneos alcançaram níveis alarmantes. Um relatório da Organização das Nações Unidas - ONU divulgado em 2019 apontou que há atualmente 272 milhões de migrantes no mundo ${ }^{3}$. Consequentemente, o crescente aumento de pedidos de refúgios levou governos de vários países a repensar políticas de atendimento às pessoas que, movidas por fatores distintos, deixam sua terra natal em busca de melhores condições de vida. A educação, sobretudo a escolar, aparece neste cenário como um instrumento decisivo para a inserção de populações imigrantes na realidade do país que os recebe, possibilitando a construção de vínculos sociais, trocas culturais e novas experiências de subjetivação, permitindo a construção de um cotidiano de vida social comunitária no novo país. A escola, neste sentido, pode ser entendida como uma das instituições decisivas neste movimento de inserção, mesmo que esta inserção ocorra, conflitivamente, sob a forma de integração, assimilação, separação (ghetização) ou marginalização dos imi-

\footnotetext{
*DOI - 10.29388/978-65-86678-45-1-0-f.207-232

${ }^{1}$ Mestranda em Educação do Programa de Pós-graduação em Educação pela Universidade Federal do Oeste do Pará (UFOPA).E-mail: simonesantana333@gmail.com

${ }^{2}$ Doutor em Educação. Professor do Instituto de Ciências da Educação, da Universidade Federal do Oeste do Pará (ICED-UFOPA).E-mail: alanaugustoribeiro@yahoo.com.br

${ }^{3}$ O Relatório sobre Migrações Mundiais 2020, o décimo da série de relatórios sobre migrações mundiais, foi produzido para contribuir para aumentar a compreensão da migração em todo o mundo. Disponível em: https://publications.iom.int/books/world-migration-report-2020. Acesso em: 29 de jul. 2020
} 
grantes em diferentes espaços sociais, sobretudo no cotidiano da escola (Munaro, 2014).

O Brasil possui fronteira com vários países da América Latina, dentre eles a Venezuela, e tem sido a principal rota de imigração de pessoas vindas deste país em decorrência da grave crise política e econômica que o assola. Dentre as pessoas que deixam a Venezuela, ganhou destaque nos noticiários brasileiros ${ }^{4}$, por suas especificidades culturais e sua dinâmica de deslocamento, a imigração dos Warao, grupo indígena considerado um dos mais antigos povos que habitam o continente. Com costumes nômades e falantes da língua tradicional Warao, têm se deslocado em grandes grupos pelo norte do Brasil, fugindo da fome e das doenças que se abateram sobre seu povo, dentro do país de origem. Ao receberem status de refugiados no Brasil, os Warao podem ter acesso às políticas públicas destinadas à imigrantes, dentre elas políticas educacionais que são concebidas com o objetivo de integrá-los a sociedade receptora, e, posteriormente, ao mercado de trabalho, para que assim possam ter certa autonomia para a própria vivência social.

A legislação educacional brasileiras não traz normativas consolidadas sobre a educação escolar para refugiados ou imigrantes. Ao lado disso, há a dificuldade que envolve as especificidades regionais e a concentração das tomadas de decisões centralizadas nas grandes capitais no sul e sudeste brasileiro. O processo histórico educacional brasileiro é marcado por um processo de constantes lutas pelo acesso e permanência de minorias brasileiras ao sistema educacional. Neste texto, abordaremos a realidade migratório dos indígenas venezuelanos Warao em Santarém em face dos instrumentos legais de apoio educacional, bem como das políticas educacionais para estes refugiados mediante a dinâmica cultural e as necessidades materiais.

\footnotetext{
${ }^{4}$ https://www.oestadonet.com.br/noticia/13209/perseguidos-no-amazonas-e-roraima-indioswarao-tem-artesanato-valorizado-em-santarem/; https://www.unicef.org/brazil/comunicadosde-imprensa/unicef-e-prefeitura-de-santarem-juntos-na-resposta-humanitaria-venezuelana; https:/g1.globo.com/pa/santarem-regiao/noticia/2020/05/22/indigena-warao-morre-com-suspeita-da-covid-19-e-mpf-recomenda-acoes-urgentes-em-santarem.ghtml
} 


\section{A chegada}

No início de 2014, os noticiários internacionais já davam ênfase a recessão econômica e a crise política que pairavam sobre a Venezuela. Não demorou muito para a recessão ganhar status de crise internacional e humanitária, causando uma das maiores crises migratórias já registradas no século $\mathrm{XXI}^{5}$. O crescente número de pessoas que deixaram o país em busca de emprego, moradia, e alimentação fez com que aumentasse exponencialmente os pedidos de refúgio em países fronteiriços, dentre eles o Brasil. Como afirma uma publicação no site da UNICEF Brasil (2020).

Com o agravamento da crise econômica e social na Venezuela, o fluxo de cidadãos venezuelanos para o Brasil cresceu maciçamente nos últimos anos. Entre 2015 e maio de 2019, o Brasil registrou mais de 178 mil solicitações de refúgio e de residência temporária. A maioria dos migrantes entra no País pela fronteira norte do Brasil, no Estado de Roraima, e se concentra nos municípios de Pacaraima e Boa Vista, capital do Estado ${ }^{6}$.

A migração venezuelana para o Brasil se apresenta como um dos grandes desafios para o governo brasileiro, pois, além de agravar uma série de problemas sociais vividos no país de origem, como acesso à saúde, moradia, alimentação de qualidade e oferta de vagas escolares para as crianças, acendeu um alerta sobre as demandas culturais de parte considerável dos refugiados que adentravam a fronteira brasileira. Referimonos aos indígenas de diversas etnias, e, na região Oeste do Pará, especificamente na cidade de Santarém, aos indígenas Warao, grupo étnico com costumes nômades que habitam/habitavam o delta do Orinoco, no Esta-

\footnotetext{
${ }^{5}$ O Grupo de Trabalho da Organização dos Estados Americanos (OEA) sobre migrantes e refugiados venezuelanos apresentou hoje seu relatório preliminar, que adverte que a migração forçada de venezuelanos ultrapassará cinco milhões de pessoas até o final de 2019 e que trata-se da segunda maior crise de migrantes e refugiados no mundo, depois daquela causada pela guerra na Síria. Disponível em: https://www.oas.org/pt/centro midia/nota imprensa.asp?sCodigo=P-009/19. Acesso em: 17 de mai.2020

${ }^{6}$ Disponível em:https://www.unicef.org/brazil/crise-migratoria-venezuelana-no-brasil. Acesso em: 04 de jun. 2020
} 
do de Delta Amacuro ${ }^{7}$ na Venezuela, em uma das regiões litorânea mais importantes do país de acesso ao oceano atlântico, à áreas marítimas, ribeirinhas e zonas úmidas como pântanos, manguezais e florestas de várzeas. Praticam a pesca e a coleta de frutos e mel, e tem como principal produto de subsistência a palma de moriche (Mauritia flexuosa) ${ }^{8}$. As habitações do povo Warao caracterizam-se como residências com teto de palha e cabanas construídas sobre palafitas para proteção contra inundações (Garcia-Castro, 2000, p.79).

A palavra Warao tem sua origem nos termos $W a h a=$ pântano e Arao $=$ habitantes, de modo que uma tradução direta seria: povos dos pântanos. Esta origem está intimamente ligada ao rio Orinoco, palavra originária de Wirinoko $($ Wiri $=$ onde se rema e Noko = local $)$ que tem no seu significado a ligação com às práticas da locomoção do povo. Porém, uma outra leitura etimológica defende que a palavra tem sua origem no termo ( $W a=$ curiara $/$ canoa e $A r a o=$ habitantes) levando ao termo mais conhecido (Warao = povo da canoa) e que dá nome tanto a etnia quanto a língua tradicional do grupo em questão (Garcia Castro, 2006, p.43).

Os Warao são considerados um dos povos mais antigos do continente Sul-Americano e conserva elementos culturais bem preservados, semelhantes aos povos encontrados no século XVI, período da colonização. De cultura nômade, se desloca em grupos familiares tendo sempre um líder idoso, o Aidamo ${ }^{10}$ que também se apresenta como chefe da tribo, sua religião não possui um nome especifico, mas suas crenças originam-se de narrativas tradicionais, de estruturas cosmológicas e de preceitos do Xamanismo ${ }^{11}$. Na estrutura de parentesco, o homem é responsável pela subsistência e a mulher pelo preparo dos alimentos e distribuição

\footnotetext{
${ }^{7}$ Outras fontes: O estado de Delta Amacuro se divide em quatro municípios: Antonio Díaz, Casacoima, Pedernales e Tucupita (capital), havendo presença Warao em todos eles. (Kuarika Naruki, 2020, p.6)

${ }^{8}$ Disponível em: https://www.infoteca.cnptia.embrapa.br/infoteca/bitstream/doc/1103403/1/ capburiti.pdf. Acesso em: 06 de jun.2020

${ }^{9} \mathrm{O}$ antropólogo Estadunidense Clifford James Geertz concebe a cultura como um complexo de significados públicos, inscritos semanticamente. Em suas palavras: "O conceito de cultura que eu defendo é essencialmente semiótico. Acreditando, como Max Weber, que o homem é um animal amarrado à teias de significados que ele mesmo teceu, assumo a cultura como sendo estas teias e suas analises, portanto, não como uma ciência experimental em busca de leis, mas como uma ciência interpretativa, à procura de significados" (Geertz, 1978, p.15)

${ }^{10}$ É uma posição social hereditária e vitalícia ligada à figura masculina e à chefia de um grupo familiar formador da comunidade.
} 
das ferramentas de trabalho. Os casamentos acontecem de acordo com as relações de parentesco e as regras de residência são uroxilocais (Garcia Castro, 2006, p. 45).

Eventos históricos de deterioração das condições de sobrevivência, invasões de suas terras por agricultores e pecuaristas, além da busca por melhores condições de subsistência em outros territórios, incluindo as grandes cidades, intensificou o Exxodo dos Warao ${ }^{12}$ para os centros urbanos venezuelanos, e posteriormente, com a crise econômica de seu país, para nações fronteiriças (Rojo, 2000). No Brasil, ao solicitar refúgio, os Warao chegam sem dominar o espanhol (língua oficial da Venezuela) e sem a compreensão da língua portuguesa (língua oficial do Brasil) o que se apresenta como uma barreira consistente ao processo de socialização e inserção nas relações comunitárias e na obtenção de possibilidades de participação no mercado de trabalho ${ }^{13}$. Em decorrência desta não inserção social em outras cidades brasileiras e em Santarém, os Warao têm vivido em estado de mendicância diante das escassas políticas de assistência social oferecidas. Não são poucas as cenas observadas onde encontramos crianças Warao nas ruas, usadas como um meio de obtenção de alguma subsistência para suas famílias ${ }^{14}$.

\section{Sobre a condição de refugiado}

A ONU definiu a categoria de refugiado, na Convenção Relativa ao Estatuto dos Refugiados de ${ }^{15} 1951$, como todas as pessoas que escapam de conflitos armados ou perseguições, apoiando-se no artigo $1^{\circ} \mathrm{da}$ Declaração Universal dos Direitos Humanos de 1948 que afirma que "todos os seres humanos nascem livres e iguais em dignidade e direitos.

\footnotetext{
${ }^{11}$ Warao Tribe. Disponível em: https://www.arcgis.com/apps/MapJournal/index.html appid $=$ cd72e623a01e471 aac4b4bb994518412. Acesso em: 05 de jun. 2020

${ }_{12}^{12}$ Disponível em: "Mendicidad indígena: Los Warao Urbano" 2000, p. 80

${ }^{13}$ https://www.bbc.com/portuguese/brasil-41587208; https://veja.abril.com.br/mundo/onusituacao-de-indios-venezuelanos-no-brasil-e-tragica/;

${ }^{14}$ Disponível em: https://www1.folha.uol.com.br/mundo/2020/01/criancas-venezuelanasvivem-de-esmolas-nas-ruas-de cuiaba.shtml

${ }^{15}$ Adotada em 28 de julho de 1951 pela Conferência das Nações Unidas de Plenipotenciários sobre o Estatuto dos Refugiados e Apátridas, convocada pela Resolução n. 429 (V) da Assembleia Geral das Nações Unidas, de 14 de dezembro de 1950. Entrou em vigor em 22 de abril de 1954, de acordo com o artigo 43. Série Tratados da ONU, Nº 2545, Vol. 189, p. 137.
} 
São dotados de razão e consciência e devem agir em relação uns aos outros com espírito de fraternidade" (Brasil 2009, p. 04).

É importante demarcar como as leis brasileiras definem a condição de refugiado. O estatuto dos Refugiados de 1951, define em seu artigo $1^{\circ}$ :

Será reconhecido como refugiado todo indivíduo que:

I - devido a fundados temores de perseguição por motivos de raça, religião, nacionalidade, grupo social ou opiniões políticas encontre-se fora de seu país de nacionalidade e não possa ou não queira acolher-se à proteção de tal país;

II - não tendo nacionalidade e estando fora do país onde antes teve sua residência habitual, não possa ou não queira regressar a ele, em função das circunstâncias descritas no inciso anterior; III - devido a grave e generalizada violação de direitos humanos, é obrigado a deixar seu país de nacionalidade para buscar refúgio em outro país.

(BRASIL, 1997).

É importante definir semanticamente os termos utilizados para classificar como refugiados a situação em que se enquadram as pessoas que migram para outros países em busca de melhores condições de vida. Os termos aqui usados para a discussão sobre a situação sócio educacional dos Warao são: refugiado e migrante. O refugiado é todo aquele que se refugia de seu país por conta de perseguições de caráter racial, religioso dentre outros e que esteja impedido de regressar ao seu país. Já o termo migrante refere-se ao indivíduo que migra de seu país para outro em decorrência de motivos familiares, casamento, melhores oportunidades de trabalho, negócios etc. O motivo não é, necessariamente, uma busca de melhores condições de vida. O Alto Comissariado das Nações Unidas para Refugiados (ACNUR) alerta que:

Confundir os termos "refugiado" e "migrante" pode gerar sérias consequências na vida e na segurança dos refugiados. Misturá-los desvia a atenção das salvaguardas legais específicas a que os refugiados têm direito. A confusão também prejudica o apoio público aos refugiados no momento em que eles mais necessitam desta 
proteção. Para o ACNUR, os direitos humanos tanto dos migrantes quanto dos refugiados devem ser inteiramente respeitados, sem perder de vista, porém, a problemática particular em que estes últimos estão enquadrados ${ }^{16}$.

O povo Warao recebe o status de refugiado no Brasil por necessitar de apoio dos órgãos públicos para que seus direitos humanitários fundamentais sejam respeitados, sobretudo em termos de subsistência alimentar. Também são considerados como refugiados porque não possuem expectativa de retorno ao seu país, tanto pela situação de grave crise econômica que a Venezuela enfrenta atualmente, quanto por não terem como garantir a manutenção de subsistência alimentar em suas terras de origem, uma vez que, na região onde habitavam, grandes petrolíferas se instalaram causando graves danos ao meio ambiente e, consequentemente, o deslocamento dos indígenas para outras regiões, para os centros urbanos e outros países do continente. Como destacam Moreira e Camargo:

As iniciativas da extração do petróleo dificultaram o acesso livre em seus territórios ancestrais, essa atividade também não registrou o emprego da mão de obra Warao. Contudo, as atividades de várias empresas petroleiras, nos estados de Monagas e Delta Amacuro, envolveu as atividades de prospecção, como explorações sísmicas, perfurações e outros, deixando como consequência a contaminação fluvial, a diminuição dos recursos pesqueiros, além das destruições de regiões de manguezais (Moreira e Camargo, 2017, p. 50)

Em 2017, quando o fluxo migratório se intensificou, os órgãos públicos tiveram que lidar com uma situação nova até então: a presença de indígenas aldeados nos centros urbanos. Como relata Farias $(2017)^{17}$

\footnotetext{
${ }^{16}$ ACNUR explica significado de status de refugiado e migrante. Disponível em: https://nacoesunidas.org/acnur-explica-significado-de-status-de-refugiado-e-migrante/. Acesso em: 16 de abr. 2020

${ }^{17}$ FARIAS, Alaíse. Crise na Venezuela: Dos 500 índios Warao refugiados metade vive embaixo de viadutos em Manaus. Amazônia Real, 2017. Disponível em: https://amazoniareal.com.br/crisena-venezuela-dos-500-indios-warao-refugiados-metade-vive-embaixo-de-viadutos-em-manaus/. Acesso em: 17 de jun.2020
} 
sobre a realidade dos Warao em Manaus, no estado do Amazonas:

Dos cerca de 500 índios Warao que migraram nos últimos cinco meses da Venezuela para Manaus, metade mora em barracas de lona em ruas e embaixo dos viadutos que ficam no entorno do Terminal Rodoviária, na zona centro-sul da capital amazonense. A falta de acolhimento humanitário, como prevê a nova Lei da Migração, criou um drama sem precedentes na cidade cuja economia vem das ricas indústrias da Zona Franca. Quem passa de ônibus ou de carro pelas vias a imagem que se vê é similar das favelas que surgiram quando Calaís, na França, abrigou refugiados Sírios.

Mesmo com a concessão da condição de refúgio aos Warao, o governo brasileiro não conseguiu de imediato garantir direitos básicos assegurados por leis e reivindicados pelos órgãos de imprensa e pela população em geral. Para que os imigrantes fossem acolhidos e a eles oferecidos ajuda humanitária, sobretudo para as crianças que se encontravam em situação de vulnerabilidade social, foi necessário que o Ministério Público Federal (MPF) acionasse órgãos responsáveis para que dessem auxílio humanitário aos Warao.

Outra preocupação das instituições é com o anúncio do $1^{\circ}$ Plano de Contingência que o governo do presidente Michel Temer (PMDB) organiza na fronteira do Brasil com a Venezuela, que pode causar restrições a vinda de refugiados índios e não índios para Manaus. Autoridades como o prefeito de Manaus, Arthur Virgílio Neto (PSDB), defendem a instalação de "um campo de refugiados e uma barreira" na fronteira para impedir a chegada de mais índios Warao na capital amazonense.

As recomendações feitas pelo MPF do Amazonas envolveu a solicitação de um trabalho pericial que deu origem ao Parecer Técnico $\mathrm{n}^{\circ} 10 / 2017^{18}$, expondo a situação precária dos indígenas Warao naquela

\footnotetext{
${ }^{18} \mathrm{O}$ documento tem como objetivo de descrever e analisar a situação dos indígenas da etnia Warao em Manaus, provenientes da região do delta do Orinoco, na Venezuela e também procura abordar as medidas adotadas até então pelo poder público e pela sociedade civil diante da perma nência das famílias Warao em Manaus e foi solicitado pelo Procurador do MPF Fernando Merlo-
} 
cidade e indicando sugestões ao governo local para que recebessem os refugiados, em situação de vulnerabilidade social. A partir deste documento, o governo municipal iniciou um processo de mobilização em busca de definições de políticas públicas que atendessem as necessidades básicas dos Warao. Cabe ressaltar que dois outros documentos foram elaborados neste sentido: Parecer Técnico No 208/2017 ${ }^{19}$ e a Peça Pericial No 01/2017/Antropologia/PR-RR/SP20.

A sugestão número 10 do Parecer Técnico n 10/2017 recomenda: "que sejam elaboradas ações e políticas públicas etnicamente diferenciadas, em conjunto com os Warao, principalmente nas áreas de saúde, educação, trabalho, moradia e abrigamento”. Ao chegarem ao Brasil, os indígenas Warao necessitavam de assistência médica, muitos apresentavam a saúde debilitada pelas longas jornadas a pé que fizeram de suas regiões até a travessia da fronteira, crianças apresentavam problemas epidérmicos, desnutrição e outras doenças. Dentre outras enfermidades, os migrantes apresentaram quadros sintomáticos de sarampo, o que exigiu a aplicação de um plano de prevenção à doença, campanhas de vacinação e imunização em grande escala. Contudo, mesmo com a vacinação, muitos indígenas acabaram contraindo a doença em 2018:

[...] Todos os casos confirmados de sarampo ocorreram em venezuelanos da etnia Warao, que chegaram dentro do período de incubação da doença, tendo passado pelos estados de Roraima e Amazonas, que enfrentam surtos de sarampo. Diante dos casos suspeitos foram aplicadas quase 600 doses de vacina tríplice viral na vacinação de bloqueio feita no local de residência e no entorno dos casos suspeitos", informou a Sesma em nota[...]. São 1.935 casos confirmados de sarampo no Brasil. O maior registro da doença ocorreu nos estados do Amazonas (1.525) e de Roraima (330), de acordo com o balanço do Ministério da Saúde divulgado no úl-

\footnotetext{
to Soave, titular do $5^{\circ}$ Ofício Cível da Procuradoria da República no Amazonas (PR-AM), e está vinculado ao Inquérito Civil no 1.13.000.000541/2017-81. (PARECER TECNICO n 10/2017)

${ }^{19}$ Sobre a situação dos Warao nas cidades de Boa Vista e Pacaraima, no estado de Roraima: um parecer concluído em março de 2017 por Luciana Ramos, Emília Botelho e Eduardo Tarragó, peritos em antropologia do MPF. (PARECER TECNICO n ${ }^{\circ}$ 10/2017)

${ }^{20}$ Peça pericial finalizada em maio de 2017, pelo perito Eduardo Tarragó, que aborda especifica mente a questão da configuração familiar dos indígenas Warao e seu acolhimento na cidade de Boa Vista. (PARECER TECNICO n 10/2017)
} 
timo dia 3, que também apontou que outros 7.974 casos suspeitos estão em investigação. De acordo com a pasta, também existem casos isolados da doença em unidades da federação, como no Pará, com 14 casos. O Estado não registrava casos de sarampo desde os únicos três confirmados em 2010. A doença voltou a aparecer no Pará em $2018^{21}$.

Os problemas de saúde são apenas um dos vários desafios enfrentados na implementação de ações de assistência aos refugiados indígenas Warao no Brasil. Assim como a saúde a educação se apresentam como um desafio fundamental a ser enfrentado, pois, por se tratar de grupo indígena de costumes nômades e que estão em deslocamento pelo país, faz-se necessário o desenvolvimento de políticas educacionais que contemplem essas especificidades. Para que possamos construir um amplo debate sobre as possibilidades de oferta de ensino adequada a um grupo indígena migrante no Brasil, faz-se necessário uma breve análise histórica da educação indígena no país, desde a colonização até a atualidade.

\section{Educação indígena no Brasil: uma breve cronologia}

A Constituição Federal de 1988 em seu artigo 205, trata do direito à educação e afirma ser direito de todos e dever do Estado e da família, demostrando assim o compromisso em proporcionar educação a todos aqueles que estiverem em território nacional. Sendo assim, todo migrante deve gozar dos mesmos direitos educacionais que o cidadão brasileiro. Mas como construir serviços escolares para imigrantes indígenas e nômades? Quais as políticas educacionais que podem ser elaboradas para este público? É possível pensar em uma rede nacional de escolarização que permita a continuidade, avaliação e progressão de nível para crianças e adolescentes migrantes, de cultura nômade, como os Warao, que estão em constante deslocamento dentro do território brasileiro? Para pensar

\footnotetext{
${ }^{21}$ SARAMPO MATOU BEBÊ WARAO EM BELÈM. O liberal, 2018. Disponível em: https://www.oliberal.com/para/sarampo-matou-beb\%C3\%AAs-warao-em-bel $\% \mathrm{C} 3 \% \mathrm{~A} 9 \mathrm{~m}$ 1.39634. Acesso em: 19 mai. 2020.
} 
essas perguntas, indicaremos um breve olhar cronológico sobre a educação para populações indígenas que pode ser dividido em três grandes marcos: a Escola de catequese, o projeto civilizatório e o ensino bilíngue.

\section{A Escola de catequese}

A chegada dos Jesuítas ao Brasil ocorreu em 1549 através da Companhia de Jesus, uma ordem religiosa que tinham como objetivo a disseminação do catolicismo e a educação no "Novo Mundo". Tinham papel importante na educação indígena, os chamados "soldados da fé", aprenderam a língua tupi-guarani e elaboraram materiais didáticos para catequisar as crianças indígenas, anulando suas tradições por considerálas ultrapassadas e selvagens, como demonstra (Soares 1961, p. 142), a Companhia de Jesus significou "uma explosão de pensamento religioso transvertido ao campo das atividades práticas. Refazer o homem, infundir-lhe espírito novo, arquetipá-lo em finalidades sociais e religiosas, foi a ação da Ordem".

\section{O projeto civilizatório}

Com a Reforma Pombalina, Marquês de Pombal tornou público o diretório do Índio instituído pelo rei de Portugal D. José I, que tinha como objetivo assegurar a liberdade aos índios, mas que trazia contrariedades, uma vez que os indígenas deveriam ter acesso aos espaços educacionais onde o ensino acontecia obrigatoriamente no idioma português e o uso da língua materna indígena era sumariamente proibido; meninos e meninas recebiam educação distintas; a nudez era proibida e a mestiçagem era estimulada. Como relata Garcia Castro:

O Diretório tinha como objetivo principal a completa integração dos índios a sociedade portuguesa, buscando não apenas o fim das discriminações sobre estes, mas a extinção das diferenças entre índios e brancos. Dessa forma, projetava um futuro no qual não seria possível distinguir uns dos outros, seja em termos físicos, por meio da miscigenação biológica, seja em termos comportamentais, 
por intermédio de uma série de dispositivos de homogeneização cultural (GARCIA, 2007, p.24).

A desobediência às diretrizes estabelecidas pela reforma Pombalina era punida até mesmo com a morte, o que confirma seu caráter apenas violento, autoritário, controlador e impositivo, o que revela o retrato de uma prática somente colonial e de imposição linguística. Neste contexto, não há preocupação com o que recentemente se concebe como respeito e tolerância. O que existem são apenas propósitos de manutenção territorial da colônia, da supremacia da religião cristão e da criminalização de práticas culturais não-europeias.

\section{O Ensino Bilingue.}

Apenas recentemente a construção histórica dos direitos dos povos indígenas no Brasil passaram a ser reconhecidos. A partir do artigo $231 \mathrm{CF} / 1988$, que dispõe que "são reconhecidos aos índios sua organização social, costumes, línguas, crenças e tradições, e os direitos originários sobre as terras que tradicionalmente ocupam, competindo à União demarcá-las, proteger e fazer respeitar todos os seus bens", institucionalizou-se a ideia de direito indígena. Assim, a lei afiança ao indígena o direito de ser quem é, e com o reconhecimento da pluralidade cultural a educação indígena, passou a "permitir" o uso de sua língua, implementando assim o Ensino Bilíngue. A Lei de Diretrizes e Bases da Educação Nacional estabeleceu em seu artigo 78 a oferta de ensino bilíngue e a interculturalidade:

O Sistema de Ensino da União, com a colaboração das agências federais de fomento à cultura e de assistência aos índios, desenvolverá programas integrados de ensino e pesquisa, para oferta de educação escolar bilíngue e intercultural aos povos indígenas, com os seguintes objetivos:

I - proporcionar aos índios, suas comunidades e povos, a recuperação de suas memórias históricas; a reafirmação de suas identidades étnicas; a valorização de suas línguas e ciências; 
II - garantir aos índios, suas comunidades e povos, o acesso às informações, conhecimentos técnicos e científicos da sociedade nacional e demais sociedades indígenas e não-índias (LDB, 1996).

A garantia da oferta de ensino escolar aos indígenas brasileiros passou a ter um lugar nos debates acadêmicos educacionais apenas recentemente, embora a ideia de "instrução" possa datar desde a colonização, quando se buscava "civilizar" as populações indígenas, moldando-as aos costumes europeus (Troquez, 2014). Nos dias atuais, a educação indígena é concebida como um instrumento de transformação social, de maneira que a educação escolar indígena para o século XXI se apresenta com o objetivo de fortalecer o diálogo entre diferentes grupos étnicos, colocando-os em posição técnica para debater com a sociedade brasileira sobre as formas e propósitos da educação que lhes é ofertada dentro e fora dos territórios étnicos, tensionando e criticando modalidades ainda assimétricas e hierarquizadas de ofertas de escolarização.

\section{Educação escolar para indígenas nômades: escolarização em deslocamento?}

Dia 28 de Setembro de 2017 foi registrada a chegada do primeiro grupo de 30 indígenas venezuelanos ao município de Santarém, que se instalaram na praça da Matriz, no centro da cidade. O grupo foi atendido pelo Conselho Tutelar do município e levados ao Centro Popular Dom Lino Vombommel ${ }^{22}$, onde receberam alimentação e em seguida foram hospedados em uma igreja evangélica. No dia 03 de outubro foram transferidos para o Centro de Formação Franciscana, ligado a Diocese de Santarém, no bairro Jardim Santarém, que lhes ofereceu suas instalações por um mês, até que a prefeitura disponibilizasse um local adequado para o acolhimento dos imigrantes. Com o crescente fluxo de deslocamentos dos Warao na região, em pouco mais de duas semanas o número de mi-

\footnotetext{
${ }^{22}$ Fundado em 30 de janeiro de 2014, O Centro POP é uma unidade pública voltada para o atendimento especializado à população em situação de rua. Realiza atendimentos individuais e coleti vos, oficinas e atividades de convívio e socialização, além de ações que incentivem o protagonismo e a participação social das pessoas em situação de rua. Disponivel em: http://www.agenciasantarem.com.br/exibe notas.asp?id nota=125. Acesso em: 16 de jun. 2020.
} 
grantes cresceu exponencialmente, passando de 30 para 90 pessoas $^{23}$, ocasionando superlotação no abrigo, o que tornou inviável a permanência dos indígenas no Centro Franciscano.

Após decisão do MPF e da Ordem dos Advogados do Brasil (OAB) de Santarém, ficou decidido pela transferência dos indígenas para a escola municipal Nossa Senhora de Fátima, que se encontrava fora de funcionamento desde 2013. A escola está situada no bairro Cambuquira, as margens da BR 163, também conhecida como Santarém/Cuiabá. No dia $1^{\circ}$ de novembro aconteceu a transferência dos Warao para esta escola. A partir desta transferência, os indígenas passaram a ser atendidos pela Secretaria Municipal de Assistência social (SEMTRAS), através da Casa de Acolhimento de Adultos e Famílias (CAAF), que é descrito como um equipamento da SEMTRAS. Como destacou o Fundo das $\mathrm{Na}$ ções Unidas para a Infância (UNICEF) que tem parceria com a Prefeitura de Santarém no apoio aos Warao:

A CAAF é um equipamento da Proteção Social Especial de Alta complexidade, cujo objetivo principal é prestar acolhida ao público adulto/familiar que esteja em vivência de situação de vulnerabilidade social. Também busca-se a inclusão desse público em ações e serviços públicos conforme preconiza a Política Nacional de Assistência Social ${ }^{24}$.

Assim como os demais Estados pelos quais os indígenas Warao se deslocaram, o município não contava com um plano de acolhimento definido, e, em pouco mais de um mês da chegada do primeiro grupo de indígenas, a SEMTRAS já contabilizava cerca de 120 pessoas em Santarém, dentre elas crianças e idosos, o que levou o governo municipal a declarar situação de emergência social ${ }^{25}$ no município. No dia $1^{\circ}$ de novem-

\footnotetext{
${ }^{23}$ Índios venezuelanos em Santarém já são mais de 90. Disponível em: https://www.oestadonet.com.br/noticia/12426/indios-venezuelanos-em-santarem-ja-sao-mais-de-9/. Acesso em: 20 jun. 2020.

${ }^{24}$ UNICEF e Prefeitura de Santarém juntos na resposta humanitária venezuelana: Disponível em: https://www.unicef.org/brazil/comunicados-de-imprensa/unicef-e-prefeitura-de-santarem-juntos-na-resposta humanitariavenezuelana. Acesso em: 17 de jun.2020.

${ }^{25}$ Disponível em: Santarém decreta situação de emergência social devido a presença de refugiados venezuelanos https://g1.globo.com/pa/santarem-regiao/noticia/santarem-decreta-situacao-de-
} 
bro, através do Decreto $n^{\circ} 796 / 2017^{26}$ a prefeitura estabeleceu, dentre outras ações, a responsabilidade de várias secretarias com relação à assistência humanitária aos Warao que se encontravam na cidade. O Decreto 796, em seu art. $5^{\circ}$ estabeleceu o seguinte: "fica sob responsabilidade da Secretaria Municipal de Educação - SEMED a inclusão da criança e do adolescente indígena na rede municipal de ensino, combatendo as situações de exclusão escolar e trabalho infantil."

A oferta de educação para refugiados no Brasil é assegurada pela Convenção de $1951^{27}$ da ONU, que define direitos e deveres das pessoas que se encontram em deslocamento pelo mundo e dos países que os acolhem. Esta convenção é reforçada pelo artigo 205 CF/1988, que garante a educação como um direito de todos. Entretanto, a oferta de educação escolar aos refugiados, na prática, esbarra em alguns "desafios" que se apresentam aos governantes, a saber, a língua, os costumes, a discriminação, a fragilidade do sistema educacional em cidades distantes dos grandes centros urbanos (e nos próprios centros urbanos), a dificuldades de implementação de políticas públicas educacionais voltadas para minorias ao lado das dificuldades de oferta de educação escolar aos cidadãos brasileiros.

Em Santarém, não se observou um processo diferente de outras cidades que acolheram precariamente os Warao. Por se tratar de um grupo com costumes nômades, o que implica um constante fluxo de migrações dentro do território nacional, incluindo deslocamentos no interior das cidades que os recebem, somado às barreiras da língua, pois em sua maioria as crianças não dominam o Espanhol e se comunicam na língua tradicional de seu povo, a inserção das crianças e adolescentes Warao na

emergencia-social-devido-a-presenca-de-refugiados-venezuelanos.ghtml. Acesso em: 16 de jun. 2020.

${ }^{26}$ Decreto $n^{\circ}$ 796/2017 - SEMGOF, de 01 de novembro de 2017. Decreta situação de emergência social no município de Santarém, devido ao intenso processo de imigração dos indígenas da etnia warao, oriundos da Venezuela, submetidos a Situação de risco pessoal e social. Disponivel em: http://www.agenciasantarem.com.br/midias/anexos/85_decreto_n796_2017_01nov17_situacao_de_emergencia_social.pdf. Acesso em: 16 de jun. 2020.

${ }^{27}$ A Convenção das Nações Unidas relativa ao Estatuto dos Refugiados foi formalmente adotada em 28 de julho de 1951 para resolver a situação dos refugiados na Europa após a Segunda Guerra Mundial. Esse tratado global define quem vem a ser um refugiado e esclarece os direitos e deveres entre os refugiados e os países que os acolhem. Disponível em: https://www.acnur.org/portugues/convencao-de-1951/. Acesso em: 10 jun. 2020. 
rede de ensino escolar municipal se caracterizou de maneira complexa, problemática e descontínua. Mesmo com o Decreto 796/2017, a matricula regular das crianças e adolescentes na rede pública de ensino apenas aconteceu um ano e meio após sua chegada ao município de Santarém, como demonstram reportagens da época:

Em março de 2019, Secretaria Municipal de Educação (SEMED) confirmou que 37 crianças e adolescentes indígenas iniciaram as atividades educacionais na escola municipal Eloina Colares e Silva. De acordo com a SEMED a medida faz parte da política de acolhimento desenvolvida pelo poder público. Eles passarão por atividades lúdicas para que possam criar o despertar de aprender a língua portuguesa, chegando a este momento de inclusão social e aprendizagem ${ }^{28}$

Acolher de forma Inter setorial. Este é o propósito da Prefeitura de Santarém desde que o município passou a receber os imigrantes venezuelanos da etnia Warao. Nesta sexta-feira, $1^{\circ}$ de março, mais uma etapa de inserção foi concluída com a introdução de trinta e sete crianças e adolescentes na Escola Municipal Eloina Colares e Silva. O início das atividades escolares foi supervisionado pelo prefeito Nélio Aguiar.

A inserção é fruto do trabalho integrado da Prefeitura com suas Secretarias, que desde setembro de 2017, acolhe, presta assistência e promove a inclusão produtiva desse povo, por meio da Secretaria Municipal de Trabalho e Assistência Social (SEMTRAS), através da CAAF. Atividades educacionais foram desenvolvidas com as crianças pela SEMED, em preparação ao momento de entrada nas escolas ${ }^{29}$

A situação dos refugiados indígenas venezuelanos é desafiadora para o governo brasileiro. Este desafio se apresenta de maneira potencialmente maior em cidades como Santarém, nas quais se concentram um alto fluxo de imigrantes indígenas brasileiros e não-brasileiros. Porém,

\footnotetext{
${ }^{28}$ https://www.oestadonet.com.br/noticia/14731/um-ano-e-meio-depois-do-primeiro-fluxomigratorio-santarem-tem-10-vezes-mais-venezuelanos-refugiados-no-municipio/. Acesso em: 22 de jul. 2020

${ }^{29}$ http://www.agenciasantarem.com.br/noticia/3485. Acesso em: 22 de jul. 2020
} 
sem a estrutura financeira e administrativa das capitais e dos grandes centros urbanos, estes desafios se tornam mais complexos. Dentre estes "desafios" envolvidos nos processos de inserção dos indígenas, é importante analisar de que forma acontece a oferta de educação escolar aos Warao no município de Santarém, região Oeste do Pará.

\section{O processo de escolarização dos Warao: primeiras im- pressões}

Regularmente matriculados na rede de ensino no ano de 2019, durante o ano de 2018 passaram inicialmente por um processo de adaptação de ensino dentro da casa de acolhimento. Foram acompanhados por professores e orientadores pedagógicos que mediaram o processo de ensino aprendizagem das crianças e adolescentes Warao, possibilitando assim a criação de uma rotina educacional para que, desta forma, pudessem ingressar nas escolas de Santarém (Matos, 2019). Inseridos no sistema regular de ensino, os desafios de inclusão se apresentaram com mais força. A rotina escolar, a adaptação com os colegas e o processo de construção de confiança com professores e membros da comunidade escolar, a integração ao ambiente escolar e suas normas, a socialização com os demais alunos e o processo de alfabetização passaram a se configurar como os aspectos centrais dos desafios enfrentados pela escola. Notouse especialmente que a criança Warao demandou das professoras um trabalho de reorganização das atividades pedagógicas na escola, demandando uma compreensão da cultura indígena e uma reorganização dos os processos de ensino oferecidos aos estudantes brasileiros em Santarém, demandando uma reformulação de algumas ideias sobre criança, infância e aprendizagem entre as professoras.

[...] A criança indígena faz em miniatura o que o adulto faz. Vive no jogo a vida dos adultos. Aprende as atividades sociais rotineiras, participa da divisão social do trabalho e adquire as habilidades de usar e fazer instrumentos e utensílios de seu trabalho, de acordo com a divisão de sexo (Meliá, 1979, p.14). 
Assim, a comunidade escolar precisou discutir o lugar da criança indígena existente no sistema de ensino infantil local. As crianças Warao, como crianças indígenas, ainda eram vistas como indivíduos dependente de atenção ou frágeis cognitivamente. Por sua vez, os adultos Warao não viam as crianças com indivíduos dependentes de proteção e cuidados, trazendo para o trabalho escolar um contraponto a essa "visão fragilizadora da criança". A criança Warao é vista como um sujeito autônomo e, desse modo, é visto entre seus familiares como alguém que precisa contribuir com a sua comunidade ativamente, devendo ser inserido no mundo do trabalho desde a tenra idade, como se pode observar nas ações das mães Warao que estão sempre acompanhadas de suas crianças ao praticarem a "coleta" nos semáforos das movimentas avenidas urbanas, como faziam na Venezuela e agora no Brasil.

O modelo Warao nos centros urbanos venezuelanos ainda parece ser o mesmo que se registra no Brasil: pedir dinheiro em pontos estratégicos (trabalho feminino) ou vender seus artesanatos. Viajam em famílias de modo a contar com homens que se encarregam de cuidar dos seus pertences, enquanto as mulheres trabalham nas ruas (Simões, 2017, p. 52)

As crianças acompanham as mães nas atividades de coleta de dinheiro nas avenidas, fato que causou estranheza na população urbana brasileira que acionou os órgãos de proteção infantil para que as crianças fossem tiradas das áreas de risco. Os órgãos de proteção infantil em parceria com o governo municipal fizeram abordagens as mães indígenas e orientações para que as crianças ficassem no abrigo ou direcionadas a escola no momento em que elas estivessem praticando tais atividades. A atitude dos órgãos de proteção infantil não foi de imediato aceita pelos Warao por ser considerada um atentado a sua cultura. A atividade de mendicância infantil vai de encontro ao que diz o artigo $5^{\circ}$ do Estatuto da Criança e do Adolescente. "Nenhuma criança ou adolescente será objeto de qualquer forma de negligência, discriminação, exploração, violência, crueldade e opressão, punido na forma da lei qualquer atentado, por ação ou omissão, aos seus direitos fundamentais". Ao serem inseridas no 
sistema de ensino escolar, as crianças deveriam ficar longe das ruas, dentro da escola. Porém, em vários dias da semana, faltavam a escola para "ir ao centro" acompanhar as mães, o que ocasionou um elevado percentual de ausência escolar durante o ano letivo de 2019.

A Prefeitura de Santarém anunciou no final da tarde desta quartafeira-feira (22), que o Conselho Tutelar vai resgatar para um local seguro os menores indígenas venezuelanos que forem encontrados em situação se risco, mesmo que acompanhados de suas mães.

Em nota, a prefeitura "reforça à população que não contribua com os pedidos de dinheiro por parte dos grupos de refugiados que vão às ruas, pois parte deles utiliza o valor para a compra de bebidas alcoólicas. Em caso de identificar crianças Venezuelanas nas ruas de Santarém, a SEMTRAS pede que a população acione o Conselho Tutelar para que o menor de idade seja resgatado em segurança" 30 .

Outro grande desafio na escolarização das crianças Warao matriculadas na rede de ensino no ano de 2019 no município de Santarém é a permanência em sala de aula. As crianças que formavam a turma de alunos regularmente matriculados na escola inicialmente contabilizava 37 alunos, mas ao final do ano letivo, contava com um número inferior a 10. O grupo que formou a primeira turma de alunos Warao possuía idades variadas que incluíam crianças em idade pré-escolar que eram atendidos em um anexo da escola onde funcionava a educação infantil. O espaço foi cedido pela comunidade (no barracão comunitário, anexo a igreja São João Batista) e abrigava duas turmas de educação infantil com alunos com idades entre 4 e 5 anos. Quatros crianças Warao foram integradas as turmas juntamente às crianças brasileiras, diferentemente do que aconteceu com as demais que foram matriculadas em uma turma específica para um suposto atendimento de suas singularidades culturais.

\footnotetext{
${ }^{30}$ Disponível em: Acionado, Conselho Tutelar vai resgatar menores venezuelanos em situação de risco nas ruas de Santarém. https:// www.oestadonet.com.br/noticia/12522/acionado-conselho-tutelar-vairesgatar-menores-venezuelanos-em-situacao-de-risco-nas-ruas-de-santarem. Acesso em: 10 jun. 2020.
} 
Em uma turma multiseriada ${ }^{31}$ foram matriculados 37 alunos e em determinado período do ano o número de alunos chegou a 43. O grupo consistia em um núcleo parental que se subdividia em aproximadamente 6 a 8 famílias que se deslocaram juntas. Quando algumas dessas famílias se deslocou da cidade, isto ocasionou a evasão da maior parte dos estudantes desta turma. É necessário lembrar que uma turma multiseriada se constitui em "turmas que são compostas por alunos de diferentes idades, series e níveis de aprendizagem. Neste tipo de organização, apenas uma professora trabalha com esses alunos na mesma sala de aula e no mesmo horário" (Medeiros, 2010, p. 29).

A turma era composta por crianças e adolescentes com idades que variavam de 7 a 19 anos, falantes da língua tradicional de seu povo Warao, alguns com pouco domínio do idioma oficial de seu país, o espanhol, e a maioria deles com pouco ou nenhum entendimento em relação a língua portuguesa. Apesar de compartilharem a mesma nacionalidade, o grupo apresentava grande heterogeneidade, tanto na faixa etária, quanto na familiaridade com o ensino.

Cabe destacar a presença de um adolescente de 15 anos e sua irmã de 11 anos que não pertenciam a etnia Warao mas, e se deslocam com o grupo. Tanto o adolescente como sua irmã frequentaram a educação formal na Venezuela, e apresentavam certa facilidade no entendimento da língua portuguesa e alguma familiaridade com a língua escrita. Uma adolescente Warao que frequentava as aulas acompanhada de seu bebê de colo e três outras adolescentes com idades entre 14 e 16 anos também frequentaram a educação formal em suas aldeias antes de sair da Venezuela, apresentando certa desenvoltura na escrita e entendimento da língua portuguesa. Porém, pouco se comunicavam em um outro idioma que não fosse o idioma tradicional de sua etnia. Estes estudantes eram os que mais se destacavam em sala de aula por mostrarem alguma capacidade de entendimento da língua portuguesa. Os demais alunos tinham idades entre 7 e 10 anos com pouco ou nenhum domínio da língua espa-

\footnotetext{
${ }^{31}$ As classes multisseriadas existem principalmente nas escolas do meio rural, visando diminuir a evasão escolar, ou em projetos específicos, baseados na metodologia da aceleração e no telecurso, buscando atrair crianças e adolescentes em situação de rua, analfabetas ou defasadas em seus estudos, para que possam aprender e serem convencidos a continuar na vida escolar. Disponível em: https://www.educabrasil.com.br/classes-multisseriadas/. Acesso em: 12 de jun.2020
} 
nhola e em sua maioria não haviam tido contato com a educação formal em seu país.

Ao assumir a turma em Abril de 2019, o grande desafio narrado pelo professor mediador foi a barreira da língua, que dificultava a comunicação com a turma. Isto, porém, não impediu o entendimento e a realização de muitas atividades em sala de aula, com participação dos indígenas Warao através de uma comunicação por meio de gestos e também do uso de um "portunhol" 32 . Na sala de aula foram fixados cartazes produzidos com a participação dos alunos e que apresentavam palavras na língua original das crianças Warao com termos do seu cotidiano e com tradução para a língua portuguesa, para que estivessem em contato simultâneo com aspectos da sua cultura e do país que os acolhe. Pelo fato de a maioria dos alunos terem uma noção de espanhol, as professoras falavam "portunhol", misturando as duas línguas (português e espanhol); na sala havia cartazes com algumas palavras ou expressões na língua warao, para os alunos manterem contato com a língua materna ${ }^{33}$.

A teoria histórico-cultural elaboradas por Vygotsky (1896-1934) afirma que as mudanças na sociedade impactam diretamente no comportamento dos sujeitos, influenciando seus processos de desenvolvimento cognitivo e, consequentemente, a evolução de seus processos psicológicos. Vygotsky demonstram que a aprendizagem está relacionada ao meio em que o indivíduo está inserido e sua troca com ele. Desse modo, o professor tem um papel fundamental no processo de adaptação do indivíduo ao ambiente de aprendizagem. Ao acompanhar os estudantes Warao, a professora responsável e a professora auxiliar da turma se tornaram responsáveis pela integração dos Warao dentro do ambiente escolar, um ambiente culturalmente estranho, ajudando-os a se familiarizar com o espaço. Também ajudaram a transmitir segurança nos processos de interação com outros membros da comunidade escolar. Mesmo com o

32 Portunhol, uma mistura de português com o espanhol. Sobre o uso do portunhol no brasil, ver: Observatório da Educação na Fronteira: Política Linguística em Contextos Plurilíngues: desafios e perspectivas para a escola/ Rosângela Morello e Marci Fileti Martins (Organização) - Florianópolis: IPOL: Editora Garapuvu, 2016 248p.

${ }^{33}$ Disponível em: Grupo de estudos quer mapear situação sociolinguística de escolas públicas do oeste paraense. https://g1.globo.com/pa/santarem-regiao/noticia/2020/02/19/grupo-de-estudos-quer-mapear-situacao-sociolinguistica-de-escolas-publicas-do-oeste-paraense.ghtml. Acesso em: 10 de jun. 2020. 
acompanhamento em sala de aula, havia também o propósito de auxiliar na construção de alguma autonomia as crianças em seu processo de adaptação àquela instituição de ensino.

O processo de adaptação entre culturas distintas deve acontecer de forma a respeitar o tempo e o espaço de cada um e em uma relação de troca entre os indivíduos. Faustino e Mota (2016, p. 401) afirmam que "Ao nascer, a criança se insere no ambiente organizado culturalmente inicia; em um, longo processo, apropriando-se dos conhecimentos necessários à medida que participa das atividades desenvolvidas pelo grupo social a que pertence".

Vale assinalar que as famílias Warao, em sua maioria, se deslocam em grupo em busca de melhores condições de vida. A situação de constante deslocamento entre as cidades criou uma rede de informações internas entre os Warao que são repassadas via celular por grupos parentais que migraram para outros estados do país, facilitando e incentivando o deslocamento destas famílias para outras capitais. O fenômeno ocasionou um alto índice de evasão na turma formada para atender as crianças indígenas, o que causou preocupação tanto para a direção da escola quanto para o governo que, ao se deparar com a situação, percebeu a ausência de políticas de conscientização e valorização da educação escolar. Por se tratar de um grupo indígena, o processo educacional não-escolar acontece de maneira informal e segue os preceitos do grupo familiar, sendo transmitido de forma oral pelos parentes mais próximos às crianças, durante o cotidiano familiar, como acontece com outros grupos indígenas do Brasil.

Florestam Fernandes, ao investigar o processo educativo entre os Tupinambá, assinala que a educação indígena objetiva preparar o sujeito, a criança, para conformar-se aos outros, mas sem perde a capacidade de realizar-se como pessoa e de ser útil à coletividade como um todo. Isso significa afirmar que o indivíduo era orientado para 'fazer' certas coisas como para 'ser' homem ou mulher, segundo os ideais de humanidade experienciados pelos grupos (Faustino e Mota, 2016, p. 399) 
Essa afirmação nos permite uma reflexão acerca da educação nos moldes ocidentais que está sendo ofertada a uma população com práticas culturais distintas e com fluxos de deslocamentos constantes que não concebem a educação da mesma forma que os outros grupos imigrantes existentes no Brasil, vindos para o país em razão dos mais variados motivos.

A legislação educacional brasileira de amparo à imigrantes segue recomendações mundiais de varios órgãos que buscam ofertar uma educação que promova a inserção sociocultural e, posteriormente, proporcione o acesso aos serviços sociais básicos, como moradia, educação e acesso ao mercado de trabalho para que assim conquistem melhores condições de vida. A legislação brasileira assegura aos indígenas educação bilíngue e processos próprios de aprendizagem, valorizando assim a sua cultura e promovendo respeito aos povos originários do País.

\section{Considerações finais}

O nono secretário-geral das Nações Unidas António Guterres em um evento sobre refugiados e imigrantes defendeu que a educação é um importante instrumento para cumprir as aspirações das pessoas e para aumentar as possibilidades de reconstrução dos seus países. Assim, a educação assume um papel importante para desenvolvimento socioeconômico das pessoas que se deslocam pelo mundo, o que leva a refletir sobre as formas de ensino que são ofertadas e quais as concepções dos imigrantes em relação a educação.

Desse modo, é importante que primeiramente se compreenda a cultura dos povos que migram, para que assim possam desenvolver políticas educacionais específicas ao atendimento dessas pessoas. Especificamente, em Santarém com o fluxo de migrantes indígenas venezuelanos as políticas educacionais devem ser pensadas sob a perspectiva das especificidades de um povo que tem como traço forte o costume nômade e a língua tradicional de seu povo.

O direito à educação é universal e instituído em diversas nações como direito fundamental, porém as políticas educacionais específicas de 
atendimento as novas configurações ${ }^{34}$ sociais ainda se apresentam como um desafio as nações que recebem povos com cultura distintas. Não basta apenas a garantia de acesso à educação formal de crianças e jovens, mas também é importante garantir permanência e inclusão do aluno, respeitando suas especificidades e para que assim a educação cumpra sua função social.

\section{Referências}

BRASIL. Parecer técnico/Manaus/SEAP/PR/AM. $\mathbf{n}^{\mathbf{0}}$ 10/2017. Sobre a situação dos indígenas Warao na cidade de Manaus. Ministério Público Federal/Amazonas.

BRASIL. [Constituição (1988)]. Constituição da República Federativa do Brasil: promulgada em 5 de outubro de 1988. 4. ed. São Paulo: Saraiva, 1990 BRASIL. Declaração dos Direitos Humanos. UNIC/RIO/005. Janeiro 2009. Disponível em: https://nacoesunidas.org/wp-content/uploads/ 2018/10/DUDH.pdf. Acesso em: 08 de jun. 2020.

BRASIL. Estatuto da Criança e do Adolescente. Lei No 8.069, de 13 de julho de 1990. Disponível em: http://www.planalto.gov.br/ccivil_03/leis/18069. Acesso em: 10 de jun. 2020.

BRASIL. Estatuto dos Refugiados. Lei n 9.474, de junho de 1997. Disponível em: http://www.planalto.gov.br/ccivil_03/leis/19474.htm. Acesso em: 18 de mai. 2020.

BRASIL. LDB - Leis de Diretrizes e Bases. Lei no 9.394. 1996. Disponível em: https://www.jusbrasil.com.br/topicos/11684035/artigo-78-da-lei-n-9394de-20-de-dezembro-de-1996. Acesso em: 17 mai. 2020

BRASIL. Parecer Técnico/SEAP $/ 6^{\circ}$ CCR/PFDC n ${ }^{\circ} 208 / 2017$, de 14 de março de 2017. Sobre a situação dos indígenas da etnia Warao, região do delta do Orinoco, nas cidades de Boa Vista e Pacaraima. Brasília: Ministério Público federal/ procuradoria geral da República.

FARIAS, Alaíse. Crise na Venezuela: Dos 500 índios Warao refugiados metade vive embaixo de viadutos em Manaus. Amazônia Real, 2017. Dis-

34 https://www.publico.pt/2016/09/20/mundo/noticia/educacao-de-refugiados-e-questao-deseguranca-global-diz-antonio-guterres-1744597. Acesso em: 12 de jul. 2020 
ponível em: https:/ / amazoniareal.com.br/crise-na-venezuela-dos-500-indioswarao-refugiados-metade-vive-embaixo-de-viadutos-em-manaus/. Acesso em: 17 de jun. 2020.

FAUSTINO, R. C; MOTA, L. T. Crianças indígenas: o papel dos jogos, das brincadeiras e da imitação na aprendizagem e no desenvolvimento. Acta Scientiarum. Education, Maringá, v. 38, n. 4, p. 395-404, 2016.

GARCÍA CASTRO, A. "Mendicidad Indígena: Los Warao Urbanos". Boletín Antropológico. Centro de Investigaciones Etnológicas - Museo Arqueológico - Universidade de Los Andes. Mérida, no 48. Enero-Abril, 2000.

GARCIA CASTRO, A. Migración de indígenas Warao para formar barrios marginales en la periferia de las ciudades de Guayana, Venezuela. Instituto Venezolano de Investigaciones Científicas (IVIC) Departamento de Antropología Caracas, Venezuela e Instituto de Investigaciones Antropológicas de Castilla y León (IIACYL). España. [Artículo publicado en: Represa Pérez, Fernando (Coordinador) (2006). De Quito a Burgos: Migraciones y Ciudadanías. Burgos España: Editorial Gran Vía. (43-48)]. 2006

GARCIA, E. F. O projeto pombalino de imposição da língua portuguesa aos índios e a sua aplicação na América meridional. Tempo, v. 12, n. 23, p. 23-38, 2007.

GEERTZ, C. A Interpretação das Culturas. Rio de Janeiro: LTC, 1978.

MEDEIROS, Maria Diva de. A escola rural e o desafio da docência em sala de aula multisseriadas: o caso de Seridó norteriograndense. 2010. Dissertação de Mestrado. Universidade Federal do Rio Grande do Norte, Natal, 2010.

MELIÀ, B. Educação indígena e alfabetização. São Paulo: Edições Loyola, 1979.

MOREIRA, Elaine; CAMARGO, Júlia. Capítulo 3 Pesquisa Qualitativa. In: DA FROTA SIMÕES, Gustavo. Perfil sociodemográfico e laboral da imigração venezuelana no Brasil. Curitiba: CVR, p. 49-81, 2017.

MUNARO, Jacqueline Graff. La adaptación de los alumnos inmigrantes: factores importantes para la educación. Perspectiva, Florianópolis, v. 32, n. 1, p. 237-255, 2014.

NARUKI, Kuarika. Comissão Interinstitucional - Educação Warao. Grupo de trabalho interinstitucional Projeto Político Pedagógico Warao. Belém, 2018 
ROJO, Antonio E. V. Los Warao e la cultura del moriche: identificacion etnohistórica y elementos culturales. Caracas: Universidad Católica, 2000. SIMÕES, Gustavo da F. Perfil sociodemográfico e laboral da imigração venezuelana no Brasil. Curitiba: CRV, 2017.

TEIXEIRA SOARES, Álvaro. O Marquês de Pombal. Brasília: Editora da UnB, 1961.

TROQUEZ, Marta. TROQUEZ, Marta Coelho Castro. Educação escolar indígena no Brasil: por uma revisão de conceitos, de políticas e de práticas. Horizontes-Revista de Educação, v. 2, n. 4, p. 49-68, 2014. 